\title{
Increased genetic counseling support improves communication of genetic information in families
}

Laura E. Forrest, BSc, Grad Dip Gen Couns ${ }^{1,2}$, Jo Burke, Grad Dip Gen Couns, PhD', Sonya Bacic, Grad Dip Gen Couns ${ }^{3}$, and David J. Amor, MBBS, PhD ${ }^{1,2,3}$

\begin{abstract}
Purpose: To determine whether the provision of additional genetic counseling support could improve the uptake of genetic services by "at-risk" relatives of probands. Methods: The Tasmanian Clinical Genetics Service implemented a specific counseling intervention to a cohort of patients who were diagnosed with a genetic condition with familial implications and compared this with a control cohort who had not experienced the specific counseling intervention. The study involved 150 family members in 19 different kindreds across the two cohorts. The principal outcome measure was the proportion of at-risk relatives who had made contact with the clinical genetics service within 2 years of the diagnosis in the index patient. Results: The proportion of at-risk relatives who made contact with the genetics service was $61 \%$ in the intervention cohort compared with $36 \%$ in the control cohort $(P=0.01)$. After controlling for the gender of the at-risk relatives, relatives in the intervention cohort were 2.6 times more likely to make contact with the genetics service $(P=0.02)$. Conclusions: The provision of increased genetic counseling support significantly increased the proportion of at-risk relatives who made contact with the genetic service. This suggests that the communication of genetic information within families can be enhanced by the provision of increased genetic counseling support. Genet Med 2008:10(3):167-172.
\end{abstract}

Key Words: genetic testing, genetic counseling, family communication, genetic information, at-risk relatives

The diagnosis of an inherited genetic condition in an individual results in the identification of at-risk relatives. Guidelines encourage genetic health professionals involved in the care of these individuals to discuss with them the implications for other relatives ${ }^{1}$ with the desired outcome being that relatives are informed of their risk. Whether this family communication actually occurs has been questioned, because of a lack of relatives presenting to genetic services for care. ${ }^{2}$

Previous research on how families communicate genetic information has demonstrated that first-degree relatives are most commonly informed in comparison with second- and third-degree relatives who are informed less frequently. ${ }^{3-7}$ Communication is often undertaken by women ${ }^{8}$ and may follow gender lines, especially for familial breast and ovarian cancer and for X-linked conditions. ${ }^{9-11}$ Information is more likely to be disseminated to relatives who are socially or emotionally close to one another ${ }^{4}$; however, individuals often report feeling a "moral obligation" to inform relatives in general. ${ }^{12} \mathrm{~A}$ com-

From the ${ }^{1}$ Murdoch Childrens Research Institute, The Royal Children's Hospital, Melbourne, Australia; ${ }^{2}$ Department of Pediatrics, The University of Melbourne, Melbourne, Australia; ${ }^{3}$ Tasmanian Clinical Genetics Service, Royal Hobart Hospital, Hobart, Australia.

David Amor, MBBS, PhD, Murdoch Childrens Research Institute, Flemington Rd, Parkville, Victoria 3052,Australia.E-mail: david.amor@mcri.edu.au.

Laura Forrest and Jo Burke contributed equally to this project.

Disclosure: The authors declare no conflict of interest.

Submitted for publication October 12, 2007.

Accepted for publication December 4, 2007.

DOI: 10.1097/GIM.0b013e318164540b mon pattern of communication described in families is where the genetic information is passed on to a "head of the family" who then takes responsibility for informing the younger generations. $^{2}$

Genetic information can be an abstract idea to comprehend and a difficult task to communicate without formal training. This problem, in conjunction with preexisting familial issues and patterns of communication within families, can reduce the efficacy of the dissemination of genetic information. ${ }^{12}$ Consultands who are faced with the task of communicating may be hindered because of feeling guilty about passing on what may be perceived as bad news to relatives. ${ }^{2}$ Other barriers encountered in families include relatives who are sick or pregnant, where a relative has died, or where relatives are estranged from one another. ${ }^{13}$ Social, geographical, or emotional distance between relatives commonly accounts for a lack of communication of genetic information. ${ }^{2}$

These actual and perceived obstacles may impact on the quality of communication undertaken in families. Substantiating this are reports that relatives are not well informed about genetic information. ${ }^{14}$ Consequently, it is unsurprising that the frequency that relatives contact the genetic service is considered low. Research has shown that the uptake of genetic testing among relatives is variable, with reports stating that between $20 \%$ and $40 \%$ of relatives clarify their genetic risk status. ${ }^{2,15}$ In this context, concern that relatives are not sufficiently aware of their risk to make an informed decision regarding contacting the genetic service for more information has resulted in efforts to assist probands to communicate. 
Suthers et al. ${ }^{16}$ implemented a method whereby letters were sent by the genetic service directly to a cohort of at-risk relatives. This intervention resulted in $40 \%$ of at-risk relatives having their genetic status clarified. This was compared with the control cohort where no contact was made with at-risk relatives and only $23 \%$ of at-risk relatives had their genetic status clarified. ${ }^{16}$ Research utilizing a genetic register to contact atrisk relatives reported similar results with $43 \%$ of the registerbased relatives having appointments with the genetics service compared with $26 \%$ of the nonregister-based relatives. ${ }^{17} \mathrm{Al}-$ though these strategies have proved effective in increasing the number of informed at-risk relatives, research also suggests that relatives prefer being informed by the proband, rather than by direct contact from the genetic service. ${ }^{17,18}$

Although families indicate a preference for communicating genetic information themselves, rather than by direct contact by the genetics service, individuals also report a need for more support from the genetics service to facilitate communication. ${ }^{2,7}$ Presently, there is a gap in published research reporting outcomes from genetics services providing increased support to individuals while they are communicating genetic information to their at-risk relatives. This study contributes data to illustrate how follow-up support provided to patients can increase at-risk relatives' awareness of a genetic condition.

\section{METHODS}

\section{Clinical setting}

The Tasmanian Clinical Genetics Service (TCGS) is located in Hobart and is the sole provider of clinical genetics services in the State of Tasmania, Australia. Tasmania has a population of approximately 485,000, and is geographically isolated from mainland Australia; therefore, patients generally do not travel to genetic services in other States for care. Historically, there has been little migration into or out of Tasmania since settlement, so that for most patients seen by the TCGS, their relatives also reside in Tasmania.

"Index patients" selected for inclusion in this study had received a genetic test result showing that they carried a gene mutation for one of the following conditions: a balanced reciprocal chromosomal translocation, hereditary breast and ovarian cancer (BRCA1 or BRCA2), hereditary nonpolyposis colorectal cancer, multiple endocrine neoplasia type 1 , Peutz-Jegher syndrome, or an X-linked condition with reproductive implications. First-degree relatives (parents, children, and siblings) were included if they were considered to be "at-risk" of the genetic condition, as defined by the mode of inheritance of the condition, the age of onset of symptoms and the availability of reproductive options. When an at-risk relative was shown to carry the family gene mutation, his or her own first-degree relatives were included. If first-degree relatives were deceased, at-risk second-degree relatives (grandparents, grandchildren, aunts, uncles, nieces, and nephews), and occasionally third-degree relatives (cousins) were included.

\section{Control cohort}

Individuals and their relatives included in the control cohort were obtained by a retrospective 2-year audit of genetic files. Families were included in the control cohort if the index patient had received a genetic test result, showing that he or she carried a pathogenic mutation, in the 18-month period between July 1, 2000, and December 31, 2001.

\section{Intervention cohort}

Individuals included in the intervention cohort received a genetic test result, showing that he or she carried a pathogenic mutation, in the 12-month period between July 1, 2003, and June 30, 2004.

For both cohorts, data were collected for 2 years after the date of disclosure of the genetic test result to the index patient, using information documented in the genetic file of the index patient detailing which of their relatives had contacted the genetic service. All study participants were counseled by the same team comprising one clinical geneticist and two genetic counselors, thereby minimizing variation in clinical practice.

\section{Intervention strategy}

A specific counseling intervention was designed to facilitate communication of genetic information from index patients to their at-risk relatives. The intervention occurred in four stages: (1) before disclosure of the genetic test result; (2) at the time of result disclosure to the index patient; (3) 2-4 weeks after result disclosure; and (4) 3-6 months after result disclosure. Table 1 details the components of the counseling intervention, including a comparison of how the issue of family communication was approached in the intervention and control cohorts.

\section{Outcome measures}

At the conclusion of the 2-year follow-up period for both cohorts, all at-risk relatives were categorized into two groups: "definitely informed" and "not definitely informed." Relatives were only considered "definitely informed" if they had made personal contact with the TCGS or an interstate genetic service. Data were also collected about whether at-risk relatives had genetic testing at that point; however, "informed status" was chosen as the primary outcome measure on the basis that clients are encouraged to make an informed choice about testing. In this context, a successful outcome might involve a client making an informed decision not to proceed with testing. Within the intervention cohort, the "not definitely informed" category was further subdivided into "apparently informed" if the genetic counselor had been told by the index patient that they had informed the at-risk relative, or "not informed" by default.

A $\chi^{2}$ test was used to assess the associations between the intervention outcome measures. Calculations were done by the EpiInfo Statistical Program (version 3.3.2; Centers for Disease Control and Prevention, USA; www.cdc.gov/epiinfo/). To adjust for the effect of gender of at-risk relatives on the association between the intervention and informed status, we con- 
Table 1

Comparison of the control and intervention cohorts

\begin{tabular}{|c|c|c|}
\hline Timeline & Control cohort & Intervention cohort \\
\hline Before result disclosure & $\begin{array}{l}\text { Pedigree reviewed and at-risk relatives identified } \\
\text { for information disclosure. }\end{array}$ & Pedigree reviewed and at-risk relatives identified for information disclosure. \\
\hline At result disclosure & $\begin{array}{l}\text { General discussion in consultation and follow- } \\
\text { up letter about importance of disclosure of } \\
\text { information to relatives. }\end{array}$ & $\begin{array}{l}\text { Specific discussion in consultation using pedigree to identify at-risk relatives and } \\
\text { facilitate discussion about importance of disclosure to at-risk relatives. } \\
\text { Follow-up letter also documented the importance of disclosure to at-risk } \\
\text { relatives. }\end{array}$ \\
\hline $\begin{array}{l}\text { 2-4 weeks post result } \\
\text { disclosure }\end{array}$ & $\begin{array}{l}\text { Telephone call to index patient as part of general } \\
\text { follow-up, focusing on personal adjustment } \\
\text { to the result rather than on notification of } \\
\text { relatives. }\end{array}$ & $\begin{array}{l}\text { Telephone call to index patient as part of general follow-up. Specific discussion } \\
\text { and documentation which at-risk relatives have been informed. If at-risk } \\
\text { relatives have not been informed, further exploration/counseling and offer of } \\
\text { guidance about how to approach relatives. }\end{array}$ \\
\hline $\begin{array}{l}\text { 3-6 months post result } \\
\text { disclosure }\end{array}$ & & $\begin{array}{l}\text { Review of family file and verification of whether at-risk relatives had made } \\
\text { contact with the genetic service. If during the } 2-4 \text { week follow-up call: ( } 1 \text { the } \\
\text { index patient denied having informed all targeted relatives; and ( } 2 \text { ) all } \\
\text { targeted relatives had not yet made contact with the genetic service, index } \\
\text { patient was recontacted and asked whether at-risk relatives had now been } \\
\text { informed. If all targeted relatives had not been informed, reasons were sought } \\
\text { and documented. Offer was made to write a letter explaining that a genetic } \\
\text { condition was in the family and suggesting that contact be made with the } \\
\text { genetic service for further information. This letter was either given to the } \\
\text { index patient for distribution or mailed directly to relatives according to } \\
\text { preference of the index patient. }\end{array}$ \\
\hline
\end{tabular}

ducted a logistic regression with informed status as the dependent variable. Gender (female compared with male) and group (intervention compared with control) were included as independent variables.

\section{RESULTS}

\section{Characteristics of study participants}

One hundred fifty participants were involved in either the control or intervention cohort. There were 72 female participants and 78 male, and the participant's ages ranged from 2 to 89 years (Table 2 ).

There were no significant differences in the gender $\left(\chi^{2}=\right.$ $1.72, P=0.19$ ) or mean age (Two-sample Wilcoxon rank-sum test, $P=0.16)$ of the at-risk relatives between the control or intervention cohorts. The control cohort comprised eight index patients and 55 at-risk relatives. In comparison, the intervention cohort comprised 11 index patients and 76 at-risk rel-

Table 2

Gender and age demographics for the control and intervention cohorts

\begin{tabular}{|c|c|c|c|c|c|}
\hline \multirow[b]{2}{*}{ Group } & \multirow[b]{2}{*}{ Number } & \multicolumn{2}{|c|}{ Gender } & \multirow{2}{*}{$\begin{array}{c}\text { Age } \\
\text { range }(y r)\end{array}$} & \multirow{2}{*}{$\begin{array}{c}\text { Mean } \\
(\mathrm{yr})\end{array}$} \\
\hline & & Male & Female & & \\
\hline \multicolumn{6}{|l|}{ Control } \\
\hline Index patients & 8 & 2 & 6 & $2-58$ & 38.13 \\
\hline At-risk relatives & 55 & 31 & 24 & $16-63$ & 42.0 \\
\hline \multicolumn{6}{|l|}{ Intervention } \\
\hline Index patients & 11 & 5 & 6 & $3-74$ & 39.18 \\
\hline At-risk relatives & 76 & 34 & 42 & $22-89$ & 49.37 \\
\hline Total & 150 & 72 & 78 & $2-89$ & 43.45 \\
\hline
\end{tabular}

atives. The genetic conditions affecting each cohort are listed in Table 3.

\section{Informed status in the intervention and control cohorts}

In the intervention cohort, $46 / 76$ (61\%) of at-risk relatives had been "definitely informed" by the index patient at the conclusion of the 2-year follow-up period, compared with 20/55 $(36 \%)$ in the control cohort (Fig. 1). This difference in the frequency that at-risk relatives were "definitely informed" between the intervention and control cohorts was statistically significant $\left(\chi^{2}=6.52, P=0.01\right)$.

There were three genetic conditions in the intervention cohort that were not present in the control cohort (Table 4); however, the difference in the frequency that at-risk relatives were "definitely informed" remained statistically significant

Table 3

Numbers of index patients and "at-risk" relatives within each cohort according to genetic condition

\begin{tabular}{lcccccc}
\hline & \multicolumn{2}{c}{ Intervention cohort } & & \multicolumn{2}{c}{ Control cohort } \\
\cline { 2 - 3 } \cline { 5 - 6 } Condition & 4 & 48 & & 5 & 47 \\
po. index & $\begin{array}{c}\text { No. at-risk } \\
\text { relatives }\end{array}$ & & $\begin{array}{c}\text { No. index } \\
\text { patients }\end{array}$ & $\begin{array}{c}\text { No. at-risk } \\
\text { relatives }\end{array}$ \\
\hline BRCA1/2 & 1 & 12 & & 0 & 0 \\
HNPCC & 1 & 2 & & 0 & 0 \\
MEN1 & 1 & 2 & & 0 & 0 \\
Peutz-Jegher syndrome & 1 & 2 & & 1 & 2 \\
X-linked condition & 3 & 10 & & 2 & 6 \\
$\begin{array}{l}\text { Balanced reciprocal } \\
\text { translocation }\end{array}$ & 11 & 76 & & 8 & 55 \\
Total & & & & & & 0 \\
\hline
\end{tabular}




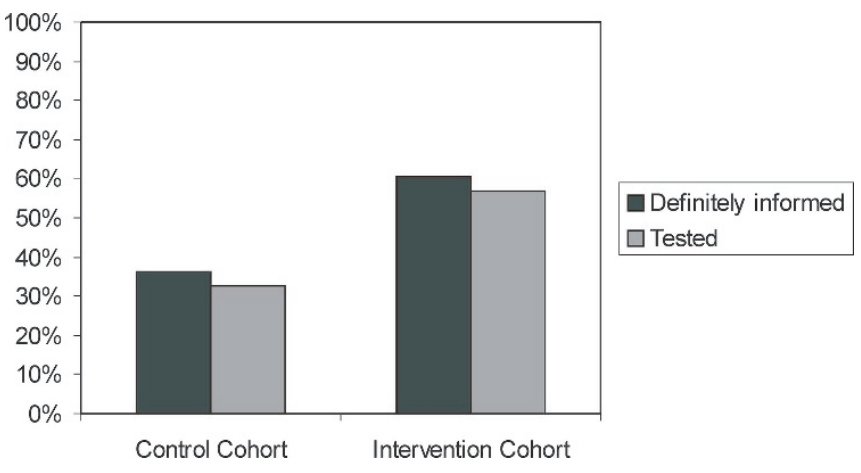

Fig. 1. Comparison between the control and intervention cohorts of the frequency of at-risk relatives that were definitely informed and underwent genetic testing.

$\left(\chi^{2}=4.01, P=0.045\right)$ even after the exclusion of conditions that were not present in both cohorts.

\section{Influence of gender on informed status}

Overall (control and intervention cohorts combined) female at-risk relatives were 5.9 times more likely to be "definitely informed" than male at-risk relatives, indicating a significant influence of gender on informed status $(P<0.001)$. After controlling for their gender, at-risk relatives in the intervention cohort were 2.6 times more likely to have been informed of their at-risk status than their counterparts in the control cohort $(P=0.02)$ (Table 5).

\section{Genetic testing in the "definitely informed" at-risk family members}

Data were also collected on the uptake of genetic testing by at-risk relatives. In the intervention cohort, 41 at-risk relatives underwent genetic testing, one declined and four were referred to interstate genetic services and so genetic testing status was not available. In the control cohort, 18 at-risk relatives underwent genetic testing and two declined. Excluding relatives who were referred interstate, the genetic testing rate was $41 / 72$ (57\%) in the intervention cohort and 18/55 (33\%) in the control cohort $\left(\chi^{2}=6.41, P=0.01\right)$ (Fig. 1).
Table 5

The influence of gender and cohort on informed status

\begin{tabular}{lccc}
\hline & $\begin{array}{c}\text { Odds } \\
\text { ratio }\end{array}$ & $\begin{array}{c}95 \% \text { Confidence } \\
\text { interval }\end{array}$ & $P$ \\
\hline Gender (female vs. male) & 5.9 & $2.7-12.8$ & $<0.001$ \\
Cohort (intervention vs. control) & 2.6 & $1.2-5.7$ & 0.02 \\
\hline
\end{tabular}

The number of at-risk relatives who were "definitely informed" and then underwent genetic testing was 18/20 (90\%) and $41 / 46(89 \%)$ for the control and intervention cohorts, respectively (Fig. 1).

Within the intervention cohort, an additional 13 at-risk relatives were "apparently informed," so that within the intervention cohort a total of 59/76 (78\%) at-risk relatives were classified as either "definitely" or "apparently" informed (Fig. 2).

\section{Intervention cohort follow-up at 3-6 months}

Of the 11 index patients in the intervention cohort (Table 3), three had successfully informed all at-risk relatives before 3 months and therefore did not require further follow-up. Eight index patients received a follow-up telephone call at 3-6

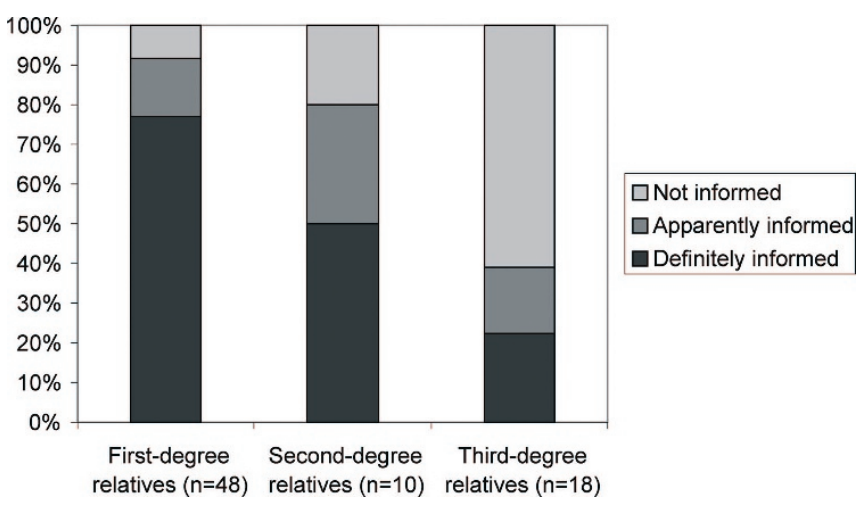

Fig. 2. Comparison of the frequencies of first-, second-, and third-degree relatives who are "definitely," "apparently," or "not informed" in the intervention cohort.

Table 4

The frequency of disclosure to at-risk relatives in the control and intervention cohorts

\begin{tabular}{|c|c|c|c|c|c|}
\hline & \multicolumn{2}{|c|}{ Intervention cohort } & \multicolumn{2}{|c|}{ Control cohort } & \multirow[b]{2}{*}{$p$ value } \\
\hline & $\begin{array}{c}\text { Definitely } \\
\text { informed, n (\%) }\end{array}$ & $\begin{array}{c}\text { Not definitely } \\
\text { informed, n (\%) }\end{array}$ & $\begin{array}{c}\text { Definitely } \\
\text { informed, n (\%) }\end{array}$ & $\begin{array}{c}\text { Not definitely } \\
\text { informed, n (\%) }\end{array}$ & \\
\hline \multicolumn{6}{|l|}{ Genetic conditions } \\
\hline BRCA $1 / 2$ & $27(56)$ & $21(44)$ & $14(30)$ & $33(70)$ & 0.01 \\
\hline HNPCC & $9(75)$ & $3(25)$ & 0 & 0 & - \\
\hline MEN1 & $2(100)$ & 0 & 0 & 0 & - \\
\hline Peutz-Jegher syndrome & $2(100)$ & 0 & 0 & 0 & - \\
\hline $\mathrm{X}$-linked condition & $2(100)$ & 0 & $2(100)$ & 0 & 1 \\
\hline Balanced reciprocal translocation & $4(40)$ & $6(60)$ & $4(67)$ & $2(33)$ & 0.30 \\
\hline Total & $46(61)$ & $30(39)$ & $20(36)$ & $35(64)$ & 0.01 \\
\hline
\end{tabular}


months. Reasons (both stated and implied) why index patients had not yet notified their at-risk relatives were varied and included the following:

- No contact for an extended period

- Did not wish to upset or worry their relative because he or she was elderly or unwell

- Did not know their address

- Were waiting for the "right moment" or for the next time they saw them

- Did not want to be the bearer of bad news

- Did not want to divulge personal health information

- Had fallen out with them

- Did not perceive the information to be important or the risk to relatives to be very high

- Were preoccupied with their own grief or health concerns

Four index patients declined and three accepted the offer of a "dear relative" letter. One index patient requested copies of the genetic service pamphlet for distribution to relatives, rather than a letter. No index patient asked that letters be sent directly to at-risk relatives by the genetics service, and at no point in the study did an index patient specifically refuse to disclose information to at-risk relatives.

\section{Informing first- to third-degree relatives}

Within the intervention cohort, the relatives can be further categorized by their degree of relatedness to the index patient. First-degree relatives were more likely to have been informed of their at-risk status compared with second- or third-degree relatives. In first-degree relatives, $37 / 48$ (77\%) were definitely informed and only 4/48 (8\%) were "not informed." In contrast, in third-degree relatives, only 4/18 (22\%) were "definitely informed" and 11/18 (61\%) were "not informed" $\left(\chi^{2}=\right.$ 24.20, $P<0.0001$ ) (Fig. 2).

\section{DISCUSSION}

One of the primary reasons for undertaking genetic testing in patients affected by inherited disorders is to provide the opportunity for clinically unaffected relatives to be informed of their genetic risk. Once informed that they are at-risk, unaffected relatives can consider predictive genetic testing themselves. This information can be used to plan future medical, reproductive, and other life decisions, with the aim of minimizing the effect of the disorder. Despite this stated aim, there is a paucity of evidence from genetic services about the frequency that patients communicate genetic information to their relatives, and whether support from the genetic service increases the proportion of informed relatives.

We have shown that a relatively simple counseling intervention consisting of additional follow-up counseling support can significantly increase $(36-61 \%)$ the proportion of close relatives who are definitely informed of their genetic risk within 2 years after the initial diagnosis in the index patient. These figures were determined by documenting the number of at-risk relatives that made contact with the genetic service, and pro- vide the most accurate indication of the effectiveness of the strategy. After controlling for gender, at-risk relatives in the intervention cohort were 2.6 times more likely to have been informed of their at-risk status at the end of the follow-up period than at-risk relatives in the control cohort. This validates our finding that the specific genetic counseling intervention significantly increases the frequency that at-risk relatives are "definitely informed" about their risk status.

We also found that female at-risk relatives were almost 6 times more likely to be "definitely informed" than male at-risk relatives. This finding is consistent with previous studies that have shown that communication in families often occurs more readily between female relatives. ${ }^{19}$

In the intervention cohort, the index patients reported that they had informed an additional $17 \%$ of at-risk relatives in addition to those who had made contact with the genetic service. For these at-risk relatives and others who are considered "not informed," it is unverifiable whether they are making an informed decision to not contact the genetics service, or whether a lack of awareness or lack of understanding of their at-risk status lies at the cause. However, when considering the intervention cohort, combining the "apparently informed" group with the "definitely informed" group, results in a potential frequency of $78 \%$ of at-risk relatives being informed of their risk status.

Although we believe that "informed status" is the preferred end point measure for a genetic counseling intervention, data were also collected regarding the number of at-risk relatives that had genetic testing to allow comparison with other studies that utilized the uptake of genetic testing as an end point. As a result of the counseling intervention, there was a similar increase in the proportion of at-risk relatives who accessed genetic testing, from $33 \%$ in the control cohort to $57 \%$ in the intervention cohort.

These results compare favorably with those achieved by other genetic services where an intervention has been employed to increase the number of informed at-risk relatives. In a previous study, an effective use of letters sent directly from the genetic service to at-risk relatives, resulted in a significant increase from $23 \%$ to $40 \%$ of relatives who had their genetic status clarified within a 2-year follow-up period. ${ }^{16}$

Follow-up methods provided by genetic services vary, where two alternative methods involve either direct contact from the genetic service to at-risk relatives or proband-mediated contact to at-risk relatives. The findings from this intervention confirm that clients prefer that information be disseminated primarily by the family, rather than by the genetics service. Of the eight index patients who had not contacted all at-risk relatives at the 3-6 month follow-up call, none accepted the offer of the genetics service making direct contact with their at-risk relatives. Four index patients accepted the offer of written material that they could pass on to their relatives. This is consistent with other studies that have cited participants who indicate that they perceive themselves rather than the genetics service as responsible for disseminating genetic information to their relatives. ${ }^{2,7,18,20}$ 
The results from this study demonstrating that first-degree relatives are more likely to be informed of their at-risk status than second- or third-degree relatives are consistent with previously published literature. In the intervention cohort, $92 \%$ of first-degree relatives were "definitely" or "apparently" informed of their at-risk status at the conclusion of the follow-up period, compared with $80 \%$ of second degree relatives and $39 \%$ of third degree relatives. These results are supported by previously published literature exploring patterns of communication in families that has shown that first-degree relatives are not only more frequently informed but often also the first people to be told genetic information. . $^{3,4,21}$

There are several limitations with the present study. Although the results of this study are highly statistically significant, the number of families involved is relatively small. There are also some differences between the control and intervention groups that cannot be controlled for, such as differences in exact diagnosis and family size. The 3-year difference between the beginning of the control and intervention cohorts may have impacted on the results of this study because of the increased awareness and social acceptance of genetics in the community. This greater awareness may have facilitated families' discussions about the genetic conditions, and resulted in at-risk relatives becoming more informed about their personal risk status. Finally, in common with other studies of this type, for at-risk relatives who do not make contact with the genetics service, it is not possible to know what information has been provided to them and why they have not made contact with the genetics service.

\section{CONCLUSION}

This study demonstrates that the provision of additional follow-up support to patients who have received genetic test results with implications for their relatives can significantly increase the number of at-risk relatives who contact the genetic service. This strategy allows individuals to retain the responsibility of informing their at-risk relatives while receiving support from the genetic service.

\section{ACKNOWLEDGMENTS}

The authors thank Veronica Collins for assisting with the statistical analysis.

\section{References}

1. Forrest LE, Delatycki MB, Skene L, Aitken M. Communicating genetic information in families-a review of guidelines and position papers. Eur J Hum Genet 2007;15: $612-618$.

2. Landsbergen K, Verhaak C, Kraaimaat F, Hoogerbrugge N. Genetic uptake in BRCA-mutation families is related to emotional and behavioral communication characteristics of index patients. Fam Cancer 2005;4:115-119.

3. Claes E, Evers-Kiebooms G, Boogaerts A, Decruyenaere M, et al. Communication with close and distant relatives in the context of genetic testing for hereditary breast and ovarian cancer in cancer patients. Am J Med Genet A 2003;116:11-19.

4. Koehly LM, Peterson SK, Watts BG, Kempf KKG, et al. A social network analysis of communication about hereditary nonpolyposis colorectal cancer genetic testing and family functioning. Cancer Epidemiol Biomarkers Prev 2003;12:304-313.

5. McGivern B, Everett J, Yager GG, Baumiller RC, et al. Family communication about positive BRCA1 and BRCA2 genetic test results. Genet Med 2004;6:503-509.

6. Ormond KE, Mills PL, Lester LA, Ross LF. Effect of family history on disclosure patterns of cystic fibrosis carrier status. Am J Med Genet C Semin Med Genet 2003; 119:70-77.

7. Gaff CL, Collins V, Symes T, Halliday J. Facilitating family communication about predictive genetic testing: proband's perceptions. J Genet Couns 2005;14:133-140.

8. d'Agincourt-Canning L. Experiences of genetic risk: disclosure and the gendering of responsibility. Bioethics 2001;15:231-247.

9. Green J, Richards M, Murton F, Statham H, et al. Family communication and genetic counseling: the case of hereditary breast and ovarian cancer. J Genet Couns 1997;6:45-60.

10. Wagner Costalas J, Itzen M, Malick J, Babb JS, et al. Communication of BRCA1 and BRCA2 results to at-risk Relatives: a cancer risk assessment program's experience. Am J Med Genet C Semin Med Genet 2003;119:11-18.

11. Julian-Reynier C, Eisinger F, Chabal F, Lasset C, et al. Disclosure to the family of breast/ovarian cancer genetic test results: patient's willingness and associated factors. Am J Med Genet 2000;94:13-18.

12. Mesters I, Ausems M, Eichhorn S, Vasen H. Informing one's family about genetic testing for hereditary non-polyposis colorectal cancer (HNPCC): a retrospective exploratory study. Fam Cancer 2005;4:163-167.

13. Julian-Reynier C, Eisinger F, Vennin P, Chabal F, et al. Attitudes towards cancer predictive testing and transmission of information to the family. J Med Genet 1996; 33:731-736.

14. Sermijn E, Goelen G, Teugels E, Kaufman L, et al. The impact of proband mediated information dissemination in families with a BRCA1/2 gene mutation. J Med Genet 2004;41:e23.

15. Clayton C, Hall P, Mackinnon M. Family screening for genetic haemochromatosis What is the most effective method of contact? Med J Aust 1993;159:614-615.

16. Suthers GK, Armstrong J, McCormack J, Trott D. Letting the family know: balancing ethics and effectiveness when notifying relatives about genetic testing for a familial disorder. J Med Genet 2006;43:665-670.

17. Kerzin-Storrar L, Wright C, Williamson PR, Fryer A, et al. Comparison of genetic services with and without genetic registers: access and attitudes to genetic counselling services among relatives of genetic clinic patients. J Med Genet 2002;39:e85.

18. Forrest K, Simpson SA, Wilson BJ, van Teijlingen ER, et al. To tell or not to tell: barriers and facilitators in family communication about genetic risk. Clin Genet 2003;64:317-326.

19. Patenaude AF, Dorval M, DiGianni LS, Schneider KA, et al. Sharing BRCA1/2 test results with first-degree relatives: factors predicting who women tell. J Clin Oncol 2006;24:700-706.

20. Hallowell N, Ardern-Jones A, Eeles R, Foster C, et al. Communication about genetic testing in families of male BRCA1/2 carriers and non-carriers: patterns, priorities and problems. Clin Genet 2005;67:492-502.

21. Forrest Keenan K, Simpson SA, Wilson BJ, van Teijlingen ER, et al. 'It's their blood not mine': who's responsible for (not) telling relatives about genetic risk? Health Risk Soc 2005; 7:209-226. 